Journal of Digitovation and Information System

http://jdiis.de/index.php/jdiis

\title{
Combined Effects of Self Tuning Model and Innovation Capability on Digital Innovation: A study of German Pharmaceutical Firm
}

\author{
Georgia Moschogianni* \\ Department of Architecture, Aristotle University, Thessaloniki, Greece
}

\begin{abstract}
Digital innovation is a buzzword for organizations in the current era to gain a competitive advantage. Grounded in the theory of entrepreneurship, this study investigates the interactive effects of innovation capability and the Self Tuning Model on digital innovation. The data was collected from 410 managerial level employees of German pharmaceutical companies using an online email survey. The results revealed that innovation capability moderated the relationship between the Self Tuning model elements and digital innovation. The study attempted to answer several unanswered questions in the digital innovation field by suggesting policy and future research directions for scholars and practitioners.
\end{abstract}

Article Information

Keywords

Innovation Capability; Digital Innovation; Pharmaceutical Firms; Organizational Agility; Organizational Adaptability; Organizational Ambidexterity

\section{Introduction}

Technological advancements have led to the creation of innovative products and services across various industries. This has enabled extraordinary transformations in business systems to adapt towards rapid changes, increase the capacity to innovate, reduce costs by utilizing knowledge sources across the organization to excel at a competitive rate (Erazo et al., 2020). Technology applications such as information systems, the internet of things, big data, chatbots, and web interactivity have enabled organizations to outreach customers, expand business operations and gain a competitive advantage (Chen et al., 2019). Especially in the pharmaceutical industry, digital innovation enables virtual checkups, 24/7 access to medical facilities, and develops electronic health records of their patients (Kraus et al., 2020). This study will explore the self-tuning model in terms of organization agility, organization adaptability, organizational ambidexterity, and innovation capability to impact digital innovation which has not been previously explored in literature.

The self-tuning model relates to the capacity of the organization to adapt timely and efficiently towards market changes through learning, technological exploration, and exploitation (Cao \& Leung, 2020). It consists of three parts: organizational agility, organization adaptability, and organization ambidexterity leading to organizations implementing product innovation management through smart manufacturing (Rodgers, 2020). This model uses algorithms to efficiently respond and adapt to customer needs. This enables companies and organizations to upgrade entire business systems to improve innovation capabilities. The main purpose of self-tuning models is to implement innovation strategies by aligning data, knowledge, people, and activities in an organization's decision-making process (Al-Saraireh et al., 2020). This study explores the role of digital innovation and its antecedents based on a self-tuning model for organizations adapting digital technologies to attain competitive advantage. Digital innovation is defined as the use of digital technology and application to improve existing business processes and workforce efficiency-enhancing the overall customer experience by introducing new and improved products and services (Mendling et al., 2020). Digital innovation enables companies to introduce new products and services more cost-effectively and efficiently. Businesses can transform, innovate and adopt new technologies to stay ahead of their competitors.

This includes $5 \mathrm{G}$ to create faster connectivity to support work from home in the current pandemic analytics through digitization utilizing big data, artificial intelligence, and machine learning (Hanelt et al., 2021). This study will explore how organizations can achieve digital innovation by enhancing their innovation capability, organization's agility, organization's adaptability, and organization's ambidexterity. 
This study contributes to the literature by enhancing the self-tuning model to include the moderating role of innovation capability leading to digital innovation which has not been previously explored in literature. Hence this study adds to the previously established literature on digital innovation and the self-tuning model. Innovation capability refers to a firm's ability to identify new ideas and transform them into new and improved products that are beneficial to the firm (Ceipek et al., 2021). It is related to the firm's efforts to integrate the firm's key resources and capabilities to successfully stimulate innovation. It includes firms' utilization of distinctive strategies to result in radical innovation that leads to developing new products and services (Di Vaio et al., 2021).

Organizational agility refers to the strategic capability that enables managers and entrepreneurs to integrate processes in an organization utilizing advanced technologies for adapting to market changes. The organization uses technologies and networks to integrate information required to maintain routines and tasks for organizational growth. Firms seek ways to agile identifying and responding to external threats (Zainal et al., 2020). Especially in highly volatile environments, requiring firms to rapidly respond and adapt towards changes and minimize resistance towards emergent trends and market needs (Gao et al., 2020). In this study, we will explore how organizational agility impacts its ability to digitally innovate and impact the firm's innovation capability which has not previously been explored.

Organizational adaptability refers to the degree to which an organization can adjust its structure, business systems, and processes to respond to external changes. This requires organizations to decentralize decision-making, increased interactivity, and enhance communication between employees and managers to align strategic goals into daily routines and processes (Akkaya \& Tabak, 2020). Organizational adaptability also requires the company to closely monitor and screen for external changes and market trends in customers and technology to respond effectively (Thom-Santelli et al., 2011). It is often symbolized with improvising and is considered essential for gaining a competitive advantage. This study will explore it in terms of its relation to digital innovation and innovation capability which previous studies have failed to address.

Finally, we will explore the role of organizational ambidexterity which is defined as an organization's ability to be aligned and efficient in managing its current enterprise systems as well as being adaptive to changes occurring in the nearby future in its environment (Maclean et al., 2020). Digital technologies require exploration and exploitation of activities to enhance development by utilizing smart tools that are targeted to increase the overall system's efficiency (Park et al., 2020). These technologies increase facilitation, reduce costs and result in improving productivity and enhanced synergy through integration. Organizations strive harder to achieve current goals while investing resources to adopt future trends through technologies and research.

This study is conducted in Germany a highly developed and technologically sufficient economy. The data is collected from pharmaceutical companies. Germany is on the cutting edge of technology and incorporates it for supporting health care (Castillo-Apraiz \& Matey, 2020). The government has recently passed laws to put Germany in the lead for digital patient-oriented healthcare globally. They have fast-tracked in the market of 82 million people, hosting more than 400,000 health care professionals dealing with various health care areas with around 300 health insurance companies and 2000 hospitals reaching their patients digitally through one click (Castillo Apraiz \& Matey de Antonio, 2020). They provide remote consultations, diagnosing, and monitoring for low health and high health risk patients. Digital pharmaceutical companies are being provided with incentives to prove that their health system increased medical efficiency and reduces health risks to patients by timely identifying and diagnosing medical symptoms (Schmidt et al., 2020). This study is based on the self-turn model for digital innovation. However, we utilize from existing literature the effectuation theory ( $\mathrm{Li}$ et al., 2020) of entrepreneurship to better explain how to study variables relate. This suggests that companies make decisions and perform actions by identifying and assessing current resources to achieve goals by formulating innovative strategies (Scazziota et al., 2020). In this study, effectuation theory supports how organizations analyze external changes and align them with internal resources and capabilities to respond by enhancing the company's innovative capabilities through digital technologies.

\section{Literature review and framework development}

\subsection{Research theory}

This study focuses on the effectuation theory of entrepreneurship to explain the phenomenon of digital innovation in organizations through the moderating role of innovation capability and the self-tuning model components. Effectuation theory is the opposite of causation logic based on planning to deal with market changes and risks. Effectuation logic on the other hand is open to surprises and avoids overly strict planning (Hukal \& Henfridsson, 2020). Since that can hurdle the adaptability and flexibility of an organization to external changes. It has been studied in literature from the entrepreneur's point of view as he is a risk-taking individual who brings new ideas to market and innovative products and services (Harms et al., 2021). This theory relates to how managers decide uncertainty especially for various SME's who lack resources since it is based on the assumption that the future is unpredictable (Saarikko et al., 2019). The technologybased firms and those operating in the IT sector face unprecedented changes through unforeseeable development in technology. The organization needs to adopt strategies to respond effectively to change (Baber et al., 2019). 
This theory is based on what organizations know (organization's agility), who they are (organization's adaptability) and whom they know (organizational ambidexterity) which is based on evaluating opportunities and building strategies in turn from enhancing performance. In the context of this study, how organizations foresee, explore, and adapt to changes in the market environment relying on innovation capability to enhance digital innovation will be studied. The organization's agility, adaptability, and ambidexterity will be explored as specific states are applied to confront uncertainty and develop new products and services.

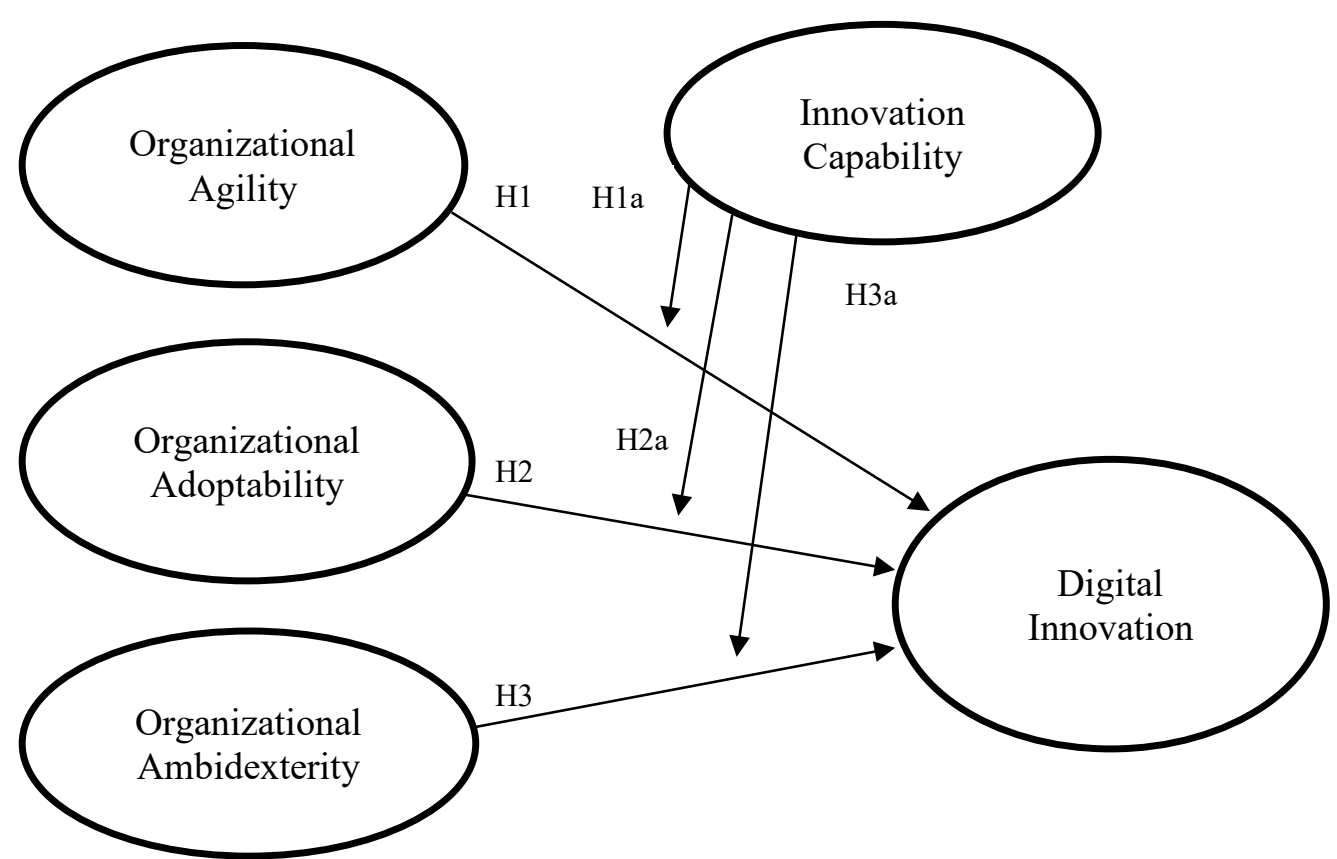

Figure 1: Research Framework

\subsection{Relationship between organization agility and digital innovation}

Literature has explored organization agility relating to customer responsiveness, IT capabilities, and strategic flexibility (Akkaya \& Tabak, 2020). The firms that are operating through ICT technologies need to be agile to face external challenges (Thom-Santelli et al., 2011). Research shows that volatile markets like crude oil, gold, bitcoin, steel mills, etc., need to change quickly and co-evolve through evolving market conditions against high risk and uncertainty (Sørensen \& Landau, 2015). Organizations can increase their agility by increasing their knowledge, market sensitivity, and fluidity in resource picking. Previous studies indicate that organizations that develop systems to monitor and respond to risks effectively can maintain their growth and development (Ravichandran, 2018). Organization agility enables organizations to react to external changes ((Leonhardt et al., 2017) rapidly. Research supports utilizing digital and IT technologies to address changes and develop innovative products (Sambamurthy et al., 2003). Firms ability to digitally innovate helps it deal with uncertain volatile and rapidly changing environments as a firm can maintain profits and maximize market share (Burchardt \& Maisch, 2019).

H1: The organizational agility of pharmaceutical companies has a positive effect on digital innovation.

\subsubsection{The moderating role of innovation capability between organization agility and digital innovation}

Research shows that digital innovation practices are often carried out inside the boundaries of an organization through inventive and entrepreneurial employees (Sørensen \& Landau, 2015). Pharmaceutical companies are trying their best to reach customers efficiently and effectively through digitizing their supply channels (Hinings et al., 2018). Innovation capability is focused on creating a value chain based on innovation through integration through exploring knowledge sources from outside, converting them into digital content, and analyzing them for the company's benefit (Saunila, 2014). This requires companies to be agile to match external and internal resources with current needs (Burchardt \& Maisch, 2019). Innovation capability enables companies to identify needs, research development, and commercialization of innovation through adoption by its users (Liao \& Wu, 2010). Therefore, organizations are focused on developing and sustaining employee innovative potential to gain maximum benefit (Dolata, 2009). The theory of 
effectuation strongly supports that the firm's innovation capabilities lead it to effective management of risks and uncertainties in the environment (Arvidsson et al., 2020). An organization's agility is linked to continuous adjustment and improvement of internal processes which can be achieved through a strong set of firm's innovation capabilities, increasing its digital innovation (Chan et al., 2019). It is argued in this study that in the case of higher values of innovation capability, digital innovation will be high among the organization. Hence we can propose that,

H1a: Innovation capability moderates the association between an organization's agility and digital innovation.

\subsection{Relationship between organizational adaptability and digital innovation}

Organizational adaptability has been studied in the literature for increasing IT abilities and investments (Smit, 2015). Organizational adaptability has been related to explaining external events and utilizing a knowledge base to adapt to them (Dolata, 2009). One author suggests that organizational adaptability derives digital innovation by aligning business models through sustaining their innovative capabilities and focusing on learning (Almahamid et al., 2010). The previous research indicates that adaptability-oriented firms take rapid action when they face market challenges (Uhl-Bien \& Arena, 2018). They continue to rely on internal and external knowledge sources to link their systems and routines with the changes occurring in the external market. Another study supports that competitive actions are based on continuously innovating and leading through developing digital options (Ciriello et al., 2018). Change adaptability is supported in an organization's systems through flexibility, interactivity, and empowerment (Fichman et al., 2014). This requires companies to combine and integrate structures, promote knowledge sharing, coordination, and implementation of strategies and processes (Liao \& $\mathrm{Wu}, 2010)$. This in turn creates opportunities for the firm to innovate and sustain a competitive advantage through the use of digital technologies. Hence we can say that,

H2. The organizational adaptability of pharmaceutical companies has a positive effect on digital innovation.

\subsubsection{The moderating role of innovation capability between organizational adaptability and digital innovation}

Literature has explored innovation in terms of being discrete, linear, and sequential with clearly ordered, differentiated and consecutive processes (Ciriello et al., 2018). Innovation is based on idea generation, advocacy, and screening, experimentation, diffusion, and implementation (Demirkan et al., 2016). Organizational innovation capability involves dynamic capabilities that are strengthened by organizational routines and processes to continuously adapt towards external changes (Fichman et al., 2014). Effectuation theory supports that organizations need to respond to external risks by evolving in ways that led them to be adaptive towards their external environments and market trends (Harms et al., 2021). A firm has to create a balance between collaboration and competition because companies deal with the scarcity of resources, knowledge, and competencies to mould themselves to sustain market changes (Almahamid et al., 2010).

Research provides evidence that companies maintain competitive advantage through organizational adaptability and innovation capabilities as the former enables the firm to build competencies and later leads to profit maximization (UhlBien \& Arena, 2018; Yeşil \& Dereli, 2013). The firm's digital innovation helps the firm lead market through the possession of unique abilities that can counter competition and satisfy customer needs (Hukal \& Henfridsson, 2020). Innovation capability hence creates the potential for adaptability for companies to innovate utilizing digital platforms and competencies successfully. In the case of higher values of innovation capability, digital Innovation will be high among the organization. Hence we can prose that,

H2a: Innovation capability moderates the association between an organization's adaptability and digital innovation.

\subsection{Relationship between organization ambidexterity and digital innovation}

Digital innovation is based on ICT, IA, and the use of various smart technologies and software that fast track changes and market trends and reacts by introducing new products and ideas that support these emerging needs (Nambisan et al., 2017). Today's era competition has been redefined through accessibility, efficiency, and digital presence of firms products and services to their customers (Tai et al., 2017). The companies that can reach and cater to the needs of the customer in minimum time are considered successful. Digital technologies enable companies to erase the time and location concept and react immediately to customers (Holotiuk \& Beimborn, 2018). This requires the organization to be ambidextrous by exploiting and exploring information through the use of technology (Leonhardt et al., 2017). Organizations can do so through interactivity tools, digital tools, and a hybrid of information systems (Wan et al., 2017). Organizations can retrieve ideas, knowledge, skills, and technologies from their external environment that can benefit them for product innovation (O'Reilly III \& Tushman, 2013). Research also supports that technology-related innovation leads to market innovation, enabling companies to carry out business activities in unique ways (Müller et al., 2019). 
H3: The organizational ambidexterity of pharmaceutical companies has a positive effect on digital innovation.

\subsubsection{The moderating role of innovation capability between organizational ambidexterity and digital innovation}

Studies suggest the balance between exploitation and exploration for achieving equilibrium considering them as mutually exclusive is necessary for achieving high performance (Andriopoulos \& Lewis, 2009; Peng, 2019). IT ambidexterity is generally considered an enabler of flexible entrepreneurial tools and adaptive solutions to develop a deep understanding of new business contexts (O'Reilly III \& Tushman, 2013). Digital companies are highly dependent upon human resource competencies and idea generation to address the trends in the market (Leonhardt et al., 2017).

Research supports that structured organizations fail to support innovative activities as employees are required to follow SOP's and confirm designed routines (Ceipek et al., 2021). At the same time, empowerment and knowledge-based systems increase innovation within a firm (Yeşil \& Dereli, 2013). Firms base their innovation capabilities on success rate factors, innovation investment return, and innovation sustainability (Lin, 2007). This requires the firm to be able to explore and exploit external resources and transform them into ideas, skills, and products that can benefit the organization (Raisch et al., 2009). Knowledge of digital conversion, which is vital for innovation success can be increased by accessing relevant internal and external knowledge (Holotiuk \& Beimborn, 2018). This requires organizational ambidexterity based upon IT technologies to build upon the organization's innovation capability that increment chance to digitally innovation (Tai et al., 2017). Higher will be the innovation capability more will be the digital innovation among the organization.

H3a: Innovation capability moderates the association between an organization's ambidexterity and digital innovation.

\subsection{Relationship between innovation capability and digital innovation}

Innovation capability is related to human resources, distinctive competencies, skills, intangible assets such as knowledge base, and technological capability to generate and market new ideas and skills (Cassia et al., 2020). Firms utilize these capabilities strategically to maximize profits and sustain competitive advantage. Firms innovative capability depends upon how firm absorbs, process, create, change and generate new technologies, routines and processes within the knowledge frontier (Çakar \& Ertürk, 2010). Technological capabilities aid firms in maintaining innovation activities and testing the feasibility of new ideas and products (Ukko et al., 2016).

Although some authors (Corsi \& Neau, 2015; Saunila, 2014) argue that technological capabilities alone build up a firm's innovation capability, it uses various resources available to the firm in the best possible way to reduce costs and increase profits. Innovation capabilities have also been linked to being a source for differentiation and creating niches to serve specific target markets (Tuominen \& Hyvönen, 2004). Although fewer studies have focused on innovation capabilities and digital innovation, innovation has been linked to enhancing companies' overall digital presence and performance (Akhavan \& Mahdi Hosseini, 2016). If a company possesses innovative capabilities, it can more successfully innovate digitally. Hence we can propose,

H4: The Innovation capability of pharmaceutical companies has a positive effect on digital innovation.

\section{Methodology}

This study follows a quantitative survey method. The data for this study was collected from pharmaceutical companies in Germany following a random sampling. Pharmaceutical companies are responsible for manufacturing and distributing drugs to be used as medications for the treatment of various illnesses. They also supply medical instruments, medical devices, and life-saving treatments to provide and sustain healthcare in a community. They are a vital industry operating in medical health care of any nation and are the backbone for various hospitals, clinics, and medical centres as pharmaceutical companies provide them with resources that aid in their medical treatment. Germany is a highly developed country and an important contributor to economic, social, and political welfare in Europe. The country excels in technological advancement and digital innovation. Germany owns top technological-based industries, assuring quality management and setting benchmarks for the rest of the world. Germany has gone through vital changes in its health care system in 2019, introducing and implementing digital transformation through digital therapeutics programs. Germany is one of the top countries spending and investing in R\&D to help introduce new technologies, systems, and processes to improve the overall living standard of their people. The German ministry of health implemented the digital healthcare act (DGV) that encompasses the future of digital technology. This includes digital health applications that will be sponsored by the country's statutory health insurance funds. Germany is setting a benchmark in digital health care by allowing 24/7 easy access to medical services through a one-click function. There are various private and public pharmaceutical companies operating in Germany and rendering their services out to people. The researcher collected the data by initially contacting various pharmaceutical companies and obtaining their permission to collect data. The researcher briefly explained the study objectives and provided the confidentiality document stating that the data collected will solely be used for the study's purpose and confidentiality. After receiving permission from 
the companies, email ids of various managers and employees were obtained to investigate how they were leading towards digital innovation in their company through various practices and the use of digital innovation enablers.

The email ids were entered in Microsoft excel, which allocated random numbers for various employees through the command "=RANDBETWEEN (RANGE)" out of the 800 emails provided. This allowed for a reduction in bias and increased the validity of the sample respondents. After obtaining the random values from the list, the employees were contacted to provide demographic information on gender, age, job position, and size of business, use of digital innovation enablers (e.g., Artificial Intelligence, Big Data \& Analytics, Additive Manufacturing, Blockchain, Precision Medicine, and Digital Therapeutics). The researcher sent the questionnaire in April 2020. This questionnaire included the respondent's characteristics and study variables measured on the Likert scale, including organizational agility, organizational ambidexterity, and organizational adaptability, and the moderator variable innovation capability. Questionnaires were sent to respondents who have previously responded to the initial confirmed consent form that was randomly generated. Soft reminders after every two weeks were sent to the respondents, requesting them to provide information on the study variables. After five months, 410 questionnaires were returned to the researcher. Out of which, 116 were discarded due to missing values and outliers. This generated an overall response rate of $59 \%$ of initially 700 questionnaires circulated.

\subsection{Measures and scales}

The questionnaire included three sections. The first section contained demographic information. The second and third sections contained study variables. All items were measured using the nominal polytomous seven-point response scale to reduce non-response and bias in the study. The organization's agility was measured utilizing 03 items including "company accommodates rapidly to market changes adapted from. Organizational adaptability was also measured using three items adapted from (Almahamid et al., 2010). These included "We regularly analyze a wide variety of opportunities for improvement and adapt our business model accordingly". Then organizational ambidexterity was also measured using three items adapted from (Tai et al., 2017), including items regarding "we explore new technologies and exploit market opportunities". The innovation capability was measured utilizing 5 items adopted from (Panayides, 2006) that included items related to how the company tries out new ideas, is creative in operating methods, etc. Finally, digital innovation was measured using three items: "We use new technologies such as big data, smart sensors, etc. to generate innovations" adapted from (Lim et al., 2015).

\section{Results}

\subsection{Profile of respondents}

The respondents' profile is shown in Table 1. The majority of responders (67 percent) were male while 33 percent were female, and between the age group of 24 and 34 (45 percent), the rest of 36 percent and 19 percent were from 35 - 35 and 46 - 56 age group. Regarding their job position, 52 percent of respondents worked as an employee, while 30 percent from the managerial position and limited numbers 18 percent were owners. Nearly half ( 41 percent) of respondents were from small $10-49$ employee's companies, 33 percent from medium-sized and the remaining 26 percent from micro-sized companies. The data showed that the most prominent digital innovation enabler was artificial intelligence with a percentage of 33 , followed by big data $\&$ analytics ( 25 percent) and additive manufacturing (19 percent). The detailed statistics are provided explained in Table 1.

Table 1: Descriptive statistics of respondents' profile $(\mathrm{N}=294)$

\begin{tabular}{|c|c|c|c|c|c|}
\hline Variable & Frequency & Percent (\%) & Variable & Frequency & Percent (\%) \\
\hline Gender & & & $\begin{array}{c}\text { Use of Digital Innovation } \\
\text { enablers }\end{array}$ & & \\
\hline Male & 198 & $67 \%$ & Artificial Intelligence & 96 & $33 \%$ \\
\hline Female & 96 & $33 \%$ & Big Data \& Analytics & 73 & $25 \%$ \\
\hline Age & & & Additive Manufacturing & 57 & $19 \%$ \\
\hline 24.34 & 131 & $45 \%$ & Block chain & 31 & $11 \%$ \\
\hline $35-45$ & 106 & $36 \%$ & Precision Medicine & 20 & $7 \%$ \\
\hline $46-56$ & 57 & $19 \%$ & Digital Therapeutics & 17 & $6 \%$ \\
\hline Job Position & & & Size of Business & & \\
\hline Owner & 53 & $18 \%$ & Micro 1-9 employees & 77 & $26 \%$ \\
\hline Manager & 87 & $30 \%$ & Small 10-49 employees & 121 & $41 \%$ \\
\hline Employee & 154 & $52 \%$ & Medium 50-250 employees & 96 & $33 \%$ \\
\hline
\end{tabular}

\subsection{Construct's descriptive statistics}


Table 2 contains the Cronbach's alpha factor loadings for the research constructs. Five constructs have Cronbach's alpha values ranging from .78 to .83 , beyond the .70 indicated by Churchill (1979). There were no significant cross-loadings and all items were loaded above the suggested benchmark of .50 (Hair et al., 2016), and KMO and Bartlett's Test also confirmed an acceptable value of .812, i.e., > .60 (Kaiser, 1974). As illustrated in Table 2, high factor loadings indicate convergent validity.

Table 2: Descriptive statistics of constructs

\begin{tabular}{|c|c|c|c|c|c|c|}
\hline & Cronbach's Alpha & 1 & 2 & 3 & 4 & 5 \\
\hline Organizational Agility & .771 & & & & & \\
\hline$\overline{\mathrm{OAg} 1}$ & & .841 & & & & \\
\hline OAg2 & & .880 & & & & \\
\hline OAg3 & & .725 & & & & \\
\hline Organizational Adaptability & .783 & & & & & \\
\hline OAd1 & & & .861 & & & \\
\hline OAd2 & & & .781 & & & \\
\hline OAd3 & & & .775 & & & \\
\hline Organizational Ambidexterity & .861 & & & & & \\
\hline OAm1 & & & & .782 & & \\
\hline OAm2 & & & & .741 & & \\
\hline OAm3 & & & & .874 & & \\
\hline Innovation Capability & .732 & & & & & \\
\hline$\overline{\mathrm{IC} 1}$ & & & & & .765 & \\
\hline IC2 & & & & & .862 & \\
\hline IC3 & & & & & .795 & \\
\hline Digital Innovation & .795 & & & & & \\
\hline$\overline{\text { DI1 }}$ & & & & & & .732 \\
\hline DI2 & & & & & & .782 \\
\hline DI3 & & & & & & .874 \\
\hline
\end{tabular}

In an additional analysis for each latent construct, we assessed composite reliability, validity, correlation, and the average variance extracted (AVE). The values of composite reliability and AVE values were typically found to be more than the suggested threshold of 0.7 and 0.5, respectively, offered evidence of dependability (Fornell \& Larcker, 1981). Squared AVE values greater than inner construct correlations indicate discriminant validity. The AVE was typically high, except innovation capability i.e., .49 and it is counted as acceptable due to reaching the suggested benchmark. The detailed findings are shown in Table 3, depicting that all constructs' internal consistency and reliabilities are quite satisfactory.

Table 3: Construct reliability, Correlation, Validity, and AVE

\begin{tabular}{lccccccc}
\hline & AVE & $\begin{array}{c}\text { Composite } \\
\text { Reliability }\end{array}$ & $\mathbf{1}$ & $\mathbf{2}$ & $\mathbf{3}$ & $\mathbf{4}$ & $\mathbf{5}$ \\
\hline Organizational Agility & .669 & .857 & $\mathbf{. 8 2}$ & & & & \\
Organizational Adoptability & .650 & .847 & $.121^{*}$ & $\mathbf{. 8 1}$ & & & \\
Organizational Ambidexterity & .641 & .842 & $.412^{* *}$ & $.772^{* *}$ & $\mathbf{. 8 0}$ & & \\
Innovation Capability & .490 & .849 & $.732^{* *}$ & $.213^{* *}$ & $.321^{*}$ & .70 & .80 \\
Digital Innovation & .637 & .839 & $.532^{* *}$ & $.453^{*}$ & $.371^{* *}$ & $.391^{*}$ & $\mathbf{. 8 0}$ \\
\hline$* * \mathrm{p}<0.05, * * * \mathrm{p}<0.01$ & & & & & & &
\end{tabular}

\subsection{Structural relationship analysis}

A structural equation model was employed to ascertain if the theoretical model adequately explained the observed relationships in the sample data (Bollen \& Long, 1993). The analysis was conducted using IBM SPSS and 26. Two models were estimated: one that was with direct relationships and the other one that was with moderation.

In the evaluation of Model 1, organizational agility, organizational adaptability, organizational ambidexterity is added 
to the model with the direct relationship with digital innovation. As shown in Figure 2, Organizational agility has a significant positive effect on digital innovation $(\beta=.312, \mathrm{p}<.000)$, indicating higher organizational agility leads to higher innovation. Thus, H1 is supported. Similarly, organizational adaptability significantly relates with digital innovation $(B=0.552, p<$ .000), thus supporting H2. Lastly, the direct relationship between organizational ambidexterity was also significantly related to digital innovation $(ß=.453, \mathrm{p}<.000)$.

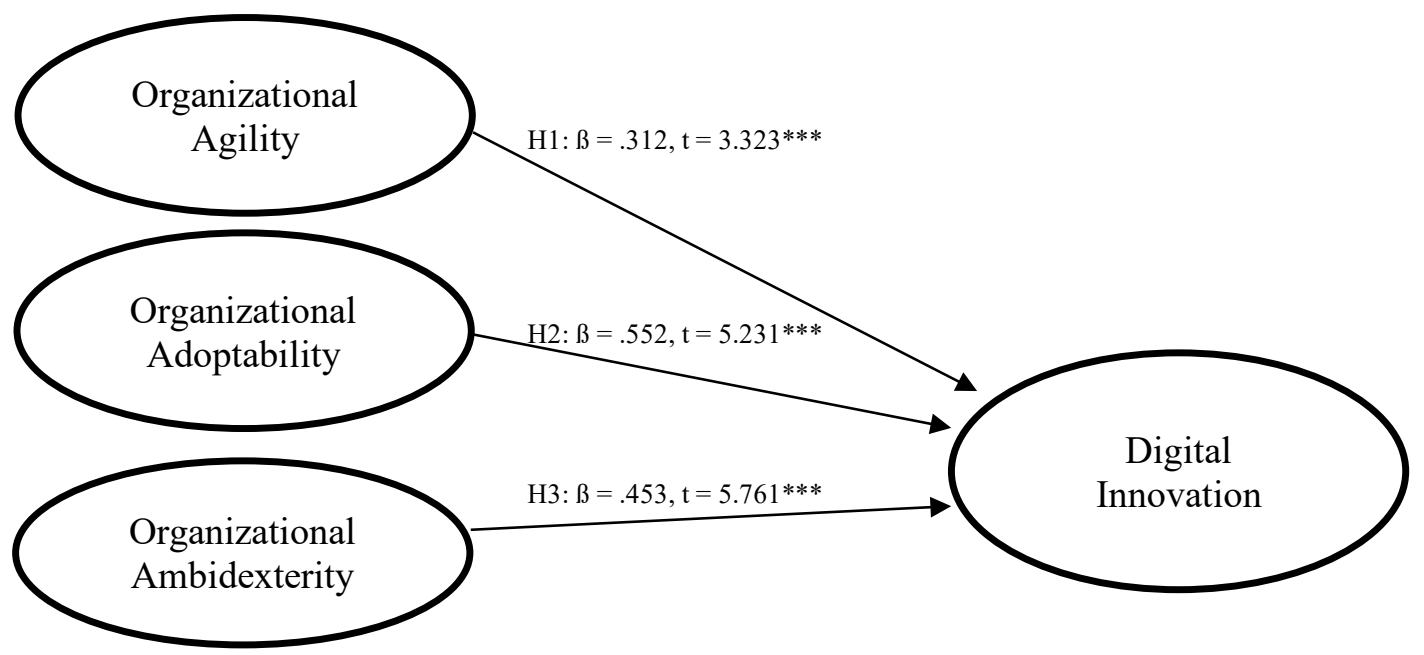

Figure 2. Result of proposed relationships

All relationships between constructs are significant after the inclusion of moderating variable in Model 2. The hypothesized moderated model results (see Table 4) suggested that innovation capability significantly moderates the organizational agility and digital innovation relationship, thus supports H1a ( $(=.321, p<.05)$. Also, support for H2a was found by noticing the high moderating effect of innovation capability between organizational adaptability and digital innovation $(\beta=.412, \mathrm{p}<.000)$. Lastly, innovation capability had a significant moderating influence on the relationship between organizational ambidexterity and digital innovation $(\beta=.109, \mathrm{p}<.05)$, thus supporting H3a. However, the other moderation relationships were not proved.

Table 4: Results of moderating analysis

\begin{tabular}{lccc}
\hline Moderation Relationships & $\begin{array}{c}\text { Standardized } \\
\text { effect }\end{array}$ & T Values & P Values \\
\hline Innovation Capability -- Digital Innovation & .241 & 3.561 & .000 \\
Innovation Capability * Organizational Agility -- Digital Innovation & .321 & 2.07 & .05 \\
Innovation Capability * Organizational Adoptability -- Digital Innovation & .412 & 4.763 & .000 \\
Innovation Capability *Organizational Ambidexterity -- Digital Innovation & .109 & 2.398 & .001 \\
\hline
\end{tabular}

Three independent variables, including organizational agility, organizational adaptability, and organizational ambidexterity, accounted for 42 percent of the variance in digital innovation. The result shows that the addition of the interaction term (moderating variable) innovation capability improves the variance explained in digital innovation 57 percent.

\section{Discussion and conclusion}

This study was based on germen pharmaceutical companies and their efforts towards digital innovation. Technological advancements enable companies to achieve unique solutions and increase user comfort by introducing new systems, processes, and products (Ghezzi, 2019). Pharmaceutical companies depend largely on maintaining a successful distribution system that reaches out to the customer in minimum time. As the current pandemic has presented various challenges to combat existing illnesses and demands, along with the widespread side effects of the virus (Kraus et al., 2020). Companies are striving to provide immediate medical care to their patients and other supplies in minimum time. Digital technologies in this scenario help companies to innovate and generate products and services based on new ideas to provide creative solutions to existing problems (Harms et al., 2021).

Therefore, this study investigated the antecedents of digital innovation and studied the moderating role of innovation capability, which has not been studied previously. The study results show that organization's agility is directly and positively 
related to digital innovation. Firms that are agile and strike a balance between exploitation and exploration are better able to respond to market changes and innovate. An organization's agility enables the company to closely monitor its external environment and rapidly transform its current resources to match external changes (Zainal et al., 2020). This is achieved through aligning time, work, location, and role of the people by asking who work, how they work, how much they work, and where they work (Clauss et al., 2020). This enables the company to assist and manage human capital so that their energies and knowledge are invested into generating useful ideas that can turn out to be profitable for the company.

The study results also showed that being adaptable increases the chance to digitally innovate. An organization's adaptability comes from flexible systems, decentralization, empowerment of employees, and a sound R\&D system to monitor and predict future changes occurring in a firm's environment (Coghlan et al., 2020). Technological changes are rapid and immense as they require companies to modify and transform existing processes to learn and adapt to new systems. Pharmaceutical companies invest heavily in R\&D not only for product development but also to make those products easily accessible to their customers through innovative technologies (Uhl-Bien \& Arena, 2018). One such aspect discussed is Digital Therapeutics which are responsible for delivering evidence-based therapeutic interventions to patients that are driven by high-quality software programs to prevent, manage, or treat a medical disorder or disease.

Then this study investigated and proved that organizational ambidexterity improves digital organizational innovation, which enables companies' awareness in a digital environment. A self-tuning enterprise signals the common ground in understanding how technologies enhance customer centrality in innovation decision-making by ensuring a sustainable and unique selling proposition (Lei et al., 2020). It improves the speediness and reactance of an organization to internal and external changes. Being ambidextrous allows companies to manage the present business based on exploitation activities as well as become adaptable towards future needs and changes through exploration (Maclean et al., 2020). A company needs to strike a balance between the two so as the current profitability is not affected by overspending and investing for future speculations.

Finally, this study explored the moderating role of the firm's innovation capability and its impact on the organization's agility and digital innovation, which showed that innovation capability enhances the first ability to digitally innovate by staying agile in highly complex environments. This enables companies to enhance their operational efficiency by aligning resources to a set of unique skills possessed by the company's human capital to generate innovative products and business solutions (Iqbal et al., 2020). Agility increases the response rate of the firm to external changes, which is enhanced and reinforced if the company possesses the ability to recognize new ideas and transform them into improved processes that benefit the firm. Innovatively capable organizations can develop and introduce new products rapidly to firms that do not imply systems that tap into their knowledge sources to generate new ideas and increase overall innovativeness (Lei et al., 2020). Digital technologies enable companies to streamline operations, integrate resources, and align objectives with routines to better adapt to external changes (Tai et al., 2017). Hence innovation capability moderates the firm's ability to digitally innovate through enhancing its adaptability to external demands and changes. Finally, firms possessing innovative capabilities are better able to concentrate on present tasks and tap into future opportunities. Therefore, our study results support that innovation capability moderates between organizational ambidexterity and digital innovation.

\section{Implications, limitations, and future directions}

\subsection{Theoretical implications}

There are many theoretical contributions of this study from whom researchers can benefit a lot. First of all, this study utilized the self-tuning model for pharmaceutical companies, which has not been investigated previously. Secondly, this study explores the moderating role of innovation capability, which has also not been studied previously and hence adds to the novelty of this study which researchers can benefit a lot from. As the study results show that it enhances the capability of the firm to be agile, adaptive, and become ambidextrous to digitally innovate efficiently. Another major contribution of this study is the use of effectuation theory which has also not been explored previously. As previous theories focus on knowledge sharing, activity theory, and organizational capability. Researchers can also utilize this study to enhance their understanding of digital innovation and what factors impact it. This study thoroughly investigates its antecedents in the form of the organization's agility, adaptability, and ambidexterity. Researchers can also utilize this study to explore an organization's agility and responsiveness towards changes. Further, this study supports how flexibility and adaptability help organizations to better shape resources and utilize technology to address consumer needs. Finally, this study is incremental in highlighting that company's focus on the attainment of set goals, along with enhancing skills and resources to better exploit future opportunities is the key to success.

\subsection{Practical implications}

Managers and policymakers can benefit a lot from this study. As pharmaceutical companies are operating in a highly competitive environment, it is critical for them to continuously innovate and provide innovative solutions that can help save thousands of lives. The adaptation of digital technologies enables companies to gain optimization. This increases the 
organization's ability to enhance the learning process through machine learning and big data, which leads to smart manufacturing. This study highlights that organizations can become agile by streamlining their operations to enhance their responsiveness in fast going rapidly changing environment. This study also supports that organization adaptability to evolving demands of volatile environments enhances their digital innovation. Managers can utilize this study to focus on which resources to invest for maintaining the current level of performance and which business functions to improve to attain and support innovation activities that can help organizations stay competitive by being ambidextrous. Finally, this study can have major implications for organizations to focus on their innovative capabilities to identify, translate, and transform newly generated ideas into profitable business solutions that companies can utilize to help achieve sustainable growth. Managers can introduce systems, training, workshops, and simulated environments that are facilitated by digital technologies that enable employees to think outside the box and help introduce new innovative solutions to existing and future needs.

\subsection{Limitations and future directions}

Although this study tried to thoroughly investigate digital innovation, the researcher faced certain limitations, which future studies can address. The study context was based on pharmaceutical companies in the German context, which is a technologically resourceful country. This can be addressed by comparing it with less developed and other digitally dependent markets such as the automotive industry, food and beverages, and FMCG's. This will allow for the translation of self -turning model into various industries. Another limitation was that this study was conducted through a quantitative close-ended questionnaire which leaves a margin of error for various issues that hinder innovative capabilities in the firm, which can be addressed by qualitative studies and in-depth interviews with managers and stakeholders to understand how the transformation of ideas take place literally in the company and what effective systems are there to store these ideas for future use and adaptability. 


\section{References}

Akhavan, P., \& Mahdi Hosseini, S. (2016). Social capital, knowledge sharing, and innovation capability: an empirical study of R\&D teams in Iran. Technology Analysis \& Strategic Management, 28(1), 96-113. https://doi.org/10.1080/09537325.2015.1072622

Akkaya, B., \& Tabak, A. (2020). The link between organizational agility and leadership: A research in science parks. Academy of Strategic Management Journal, 19(1), 1-17.

Al-Saraireh, Y. R., Akkaya, M., \& Sari, A. (2020). Government data analytics, innovative, absorptive and citizens-demand sensing capability: a fuzzy set analysis. International Journal of Services Operations Informatics, 10(4), 288-304.

Almahamid, S., McAdams, A. C., \& Kalaldeh, T. (2010). The Relationships among Organizational Knowledge Sharing Practices, Employees' Learning Commitments, Employees' Adaptability, and Employees' Job Satisfaction: An Empirical Investigation of the Listed Manufacturing Companies in Jordan. Interdisciplinary Journal of Information, Knowledge Management, 5.

Andriopoulos, C., \& Lewis, M. W. (2009). Exploitation-exploration tensions and organizational ambidexterity: Managing paradoxes of innovation. Organization science, 20(4), 696-717.

Arvidsson, H. G., Coudounaris, D. N., \& Arvidsson, R. (2020). The shift from causation to effectuation for international entrepreneurs: Attitudes and attitude change versus social representations. International Journal of Entrepreneurship, 24(3), 1-23.

Baber, W. W., Ojala, A., \& Martinez, R. (2019). Effectuation logic in digital business model transformation. Journal of Small Business and Enterprise Development, 26(6/7), 811-830. https://doi.org/10.1108/JSBED-04-2019-0139

Bollen, K. A., \& Long, J. S. (1993). Testing structural equation models (Vol. 154). Sage.

Burchardt, C., \& Maisch, B. (2019). Digitalization needs a cultural change-examples of applying Agility and Open Innovation to drive the digital transformation. Procedia CIRP, 84, 112-117.

Çakar, N. D., \& Ertürk, A. (2010). Comparing Innovation Capability of Small and Medium-Sized Enterprises: Examining the Effects of Organizational Culture and Empowerment. Journal of Small Business Management, 48(3), 325-359. https://doi.org/10.1111/j.1540-627X.2010.00297.x

Cao, S., \& Leung, D. (2020). Credit constraints and productivity of SMEs: Evidence from Canada. Economic Modelling, 88, 163-180.

Cassia, A. R., Costa, I., da Silva, V. H. C., \& de Oliveira Neto, G. C. (2020). Systematic literature review for the development of a conceptual model on the relationship between knowledge sharing, information technology infrastructure, and innovative capability. Technology Analysis Strategic Management, 32(7), 801-821.

Castillo-Apraiz, J., \& Matey, J. (2020). Customizing competitive strategy to entry timing: Implications for firm performance in the pharmaceutical industry. Managerial Decision Economics, 41(6), 976-985.

Castillo Apraiz, J., \& Matey de Antonio, J. (2020). The mediating role of personnel training between innovation and performance: Evidence from the German pharmaceutical industry. Cuadernos de Gestión, 20, 41-52

Ceipek, R., Hautz, J., De Massis, A., Matzler, K., \& Ardito, L. (2021). Digital transformation through exploratory and exploitative internet of things innovations: The impact of family management and technological diversification. Journal of Product Innovation Management, 38(1), 142-165.

Chan, C. M., Teoh, S. Y., Yeow, A., \& Pan, G. (2019). Agility in responding to disruptive digital innovation: Case study of an SME. Information Systems Journal, 29(2), 436-455.

Chen, X., Wei, S., Sun, C., \& Liu, Y. (2019). How technology support for contextualization affects enterprise social media use: A media system dependency perspective. IEEE Transactions on Professional Communication, 62(3), 279-297.

Churchill, G. A. (1979). A paradigm for developing better measures of marketing constructs. Journal of Marketing Research, 16(1), 64-73.

Ciriello, R. F., Richter, A., \& Schwabe, G. (2018). Digital innovation. Business Information Systems Engineering, 60(6), 563569.

Clauss, T., Kraus, S., Kallinger, F. L., Bican, P. M., Brem, A., \& Kailer, N. (2020). Organizational ambidexterity and competitive advantage: The role of strategic agility in the exploration-exploitation paradox. Journal of Innovation \& Knowledge, ahead of print(ahead of print).

Coghlan, C., Labrecque, J., Ma, Y., \& Dube, L. (2020). A Biological Adaptability Approach to Innovation for Small and Medium Enterprises (SMEs): Strategic Insights from and for Health-Promoting Agri-Food Innovation. Sustainability, 12(10), 4227.

Corsi, P., \& Neau, E. (2015). Evaluating the Ability to Innovate (Innovation Capability Maturity Model (pp. 13-19). https://doi.org/https://doi.org/10.1002/9781119144335.ch2

Demirkan, H., Spohrer, J. C., \& Welser, J. J. (2016). Digital innovation and strategic transformation. IT Professional, 18(6), 14-18.

Di Vaio, A., Palladino, R., Pezzi, A., \& Kalisz, D. E. (2021). The role of digital innovation in knowledge management systems: A systematic literature review. Journal of Business Research, 123, 220-231.

Dolata, U. (2009). Technological innovations and sectoral change: Transformative capacity, adaptability, patterns of change: An analytical framework. Research policy, 38(6), 1066-1076.

Erazo, S. C. R., Paz, D. A., \& Cardona, J. A. (2020). Contribution of Information Technology and Communications to productivity in SMEs in Santiago de Cali. (Ed.), ${ }^{(E d s .) . ~} 2020$ 15th Iberian Conference on Information Systems and Technologies (CISTI).

Fichman, R. G., Dos Santos, B. L., \& Zheng, Z. (2014). Digital innovation as a fundamental and powerful concept in the information systems curriculum. MIS quarterly, 38(2), 329-A315.

Fornell, C., \& Larcker, D. F. (1981). Evaluating structural equation models with unobservable variables and measurement error. Journal of Marketing Research, 18(1), 39-50. 
Gao, P., Zhang, J., Gong, Y., \& Li, H. (2020). Effects of technical IT capabilities on organizational agility. Industrial Management Data Systems, 120(5), 941-961.

Ghezzi, A. (2019). Digital startups and the adoption and implementation of Lean Startup Approaches Effectuation, Bricolage and Opportunity Creation in practice. Technological Forecasting Social Change, 146, 945-960.

Hair, J. F., Hult, G. T. M., Ringle, C., \& Sarstedt, M. (2016). A Primer on Partial Least Squares Structural Equation Modeling (PLS-SEM). Sage.

Hanelt, A., Firk, S., Hildebrandt, B., \& Kolbe, L. M. (2021). Digital M\&A, digital innovation, and firm performance: an empirical investigation. European Journal of Information Systems, 30(1), 3-26.

Harms, R., Alfert, C., Cheng, C.-F., \& Kraus, S. (2021). Effectuation and causation configurations for business model innovation: Addressing COVID-19 in the gastronomy industry. International Journal of Hospitality Management, $95,102896$.

Hinings, B., Gegenhuber, T., \& Greenwood, R. (2018). Digital innovation and transformation: An institutional perspective. Information Organization, 28(1), 52-61.

Holotiuk, F., \& Beimborn, D. (2018). Organizational Ambidexterity for Digital Innovation: The Approach of Digital Innovation Labs. Academy of Management Global Proceedings, Surrey(2018), 22.

Hukal, P., \& Henfridsson, O. (2020). Digital innovation-a definition and integrated perspective (The Routledge companion to management information systems. Routledge.

Iqbal, S., Rasheed, M., Khan, H., \& Siddiqi, A. (2020). Human resource practices and organizational innovation capability: role of knowledge management. VINE Journal of Information and Knowledge Management Systems, ahead-ofprint(ahead-of-print). https://doi.org/10.1108/VJIKMS-02-2020-0033

Kaiser, H. F. (1974). An index of factorial simplicity. Psychometrika, 39(1), 31-36.

Kraus, S., Clauss, T., Breier, M., Gast, J., Zardini, A., \& Tiberius, V. (2020). The economics of COVID-19: initial empirical evidence on how family firms in five European countries cope with the corona crisis. International Journal of Entrepreneurial Behavior Research, 26(5), 1067-1092.

Lei, H., Leaungkhamma, L., \& Le, P. B. (2020). How transformational leadership facilitates innovation capability: the mediating role of employees' psychological capital. Leadership \& Organization Development Journal, 41(4), 481499. https://doi.org/10.1108/LODJ-06-2019-0245

Leonhardt, D., Haffke, I., Kranz, J., \& Benlian, A. (2017). Reinventing the IT function: the role of IT agility and IT ambidexterity in supporting digital business transformation. (Ed.), $($ Eds.). In Proceedings of the 25th European Conference on Information Systems (ECIS), Guimarães, Portugal.

Li, Y., Zou, B., Guo, F., \& Guo, J. (2020). Academic entrepreneurs' effectuation logic, role innovation, and academic entrepreneurship performance: an empirical study. International Entrepreneurship Management Journal, 26(5), 124

Liao, S.-H., \& Wu, C.-c. (2010). System perspective of knowledge management, organizational learning, and organizational innovation. Expert Systems with Applications, https://doi.org/https://doi.org/10.1016/j.eswa.2009.06.109

Lim, M. F., Ooi, C. Y., \& Kwan, C. L. (2015). Smart home.

Lin, H. F. (2007). Knowledge sharing and firm innovation capability: an empirical study. International Journal of Manpower, 28(3/4), 315-332. https://doi.org/10.1108/01437720710755272

Maclean, M., Harvey, C., Golant, B. D., \& Sillince, J. A. (2020). The role of innovation narratives in accomplishing organizational ambidexterity. Strategic Organization, 19(2), 1476127019897234.

Mendling, J., Pentland, B. T., \& Recker, J. (2020). Building a complementary agenda for business process management and digital innovation. European Journal of Information Systems, 29(3).

Müller, S. D., Påske, N., \& Rodil, L. (2019). Managing ambidexterity in startups pursuing digital innovation. Communications of the Association for Information Systems, 44(1), 18.

Nambisan, S., Lyytinen, K., Majchrzak, A., \& Song, M. (2017). Digital Innovation Management: Reinventing innovation management research in a digital world. Mis Quarterly, 41(1).

O'Reilly III, C. A., \& Tushman, M. L. (2013). Organizational ambidexterity: Past, present, and future. Academy of management Perspectives, 27(4), 324-338.

Panayides, P. (2006). Enhancing innovation capability through relationship management and implications for performance. European Journal of Innovation Management, 9(4), 466-483.

Park, Y., Pavlou, P. A., \& Saraf, N. (2020). Configurations for achieving organizational ambidexterity with digitization. Information Systems Research, 31(4), 1376-1397.

Peng, H. (2019). Organizational ambidexterity in public non-profit organizations: interest and limits. Management Decision, 57(1), 248-261. https://doi.org/10.1108/MD-01-2017-0086

Raisch, S., Birkinshaw, J., Probst, G., \& Tushman, M. L. (2009). Organizational ambidexterity: Balancing exploitation and exploration for sustained performance. Organization science, 20(4), 685-695.

Ravichandran, T. (2018). Exploring the relationships between IT competence, innovation capacity, and organizational agility. The Journal of Strategic Information Systems, 27(1), 22-42.

Rodgers, K. D. (2020). Required Elements for Constructing a Highly Adaptable and Adaptive Digital Forensic Model, Capella University].

Saarikko, T., Jonsson, K., \& Burström, T. (2019). Software platform establishment: effectuation and entrepreneurial awareness. Information Technology People, 32(3), 579-602.

Sambamurthy, V., Bharadwaj, A., \& Grover, V. (2003). Shaping agility through digital options: Reconceptualizing the role of information technology in contemporary firms. MIS quarterly, 27(2), 237-263.

Saunila, M. (2014). Innovation capability for SME success: perspectives of financial and operational performance. Journal of Advances in Management Research, 11(2), 163-175. https://doi.org/10.1108/JAMR-11-2013-0063 
Scazziota, V. V., Andreassi, T., Serra, F. A. R., \& Guerrazzi, L. (2020). Expanding knowledge frontiers in entrepreneurship: examining bricolage and effectuation. International Journal of Entrepreneurial Behavior

Research, 26(5), 1043-1065.

Schmidt, A., Uhlenbrock, L., \& Strube, J. (2020). Technical Potential for Energy and GWP Reduction in ChemicalPharmaceutical Industry in Germany and EU-Focused on Biologics and Botanicals Manufacturing. Processes, $8(7), 818$.

Smit, J. (2015). The innovation value chain and adaptability of organizations. Journal of International Technology Information Management, 24(3), 4.

Sørensen, C., \& Landau, J. S. (2015). Academic agility in digital innovation research: The case of mobile ICT publications within information systems 2000-2014. The Journal of Strategic Information Systems, 24(3), 158-170.

Tai, J. C., Wang, E. T., \& Wang, K. (2017). Investigating the Impact of IT Ambidexterity on Digital Innovation Capability. (Ed.), $\wedge^{(E d s .) . ~ P a c i f i c ~ A s i a ~ C o n f e r e n c e ~ o n ~ I n f o r m a t i o n ~ S y s t e m s ~(P A C I S . ~}$

Thom-Santelli, J., Millen, D. R., \& Gergle, D. (2011). Organizational acculturation and social networking. (Ed.),^(Eds.). Proceedings of the ACM 2011 conference on Computer supported cooperative work.

Tuominen, M., \& Hyvönen, S. (2004). Organizational Innovation Capability: A Driver for Competitive Superiority in Marketing Channels. The International Review of Retail, Distribution and Consumer Research, 14(3), 277-293. https://doi.org/10.1080/09593960410001678417

Uhl-Bien, M., \& Arena, M. (2018). Leadership for organizational adaptability: A theoretical synthesis and integrative framework. The Leadership Quarterly, 29(1), 89-104.

Ukko, J., Saunila, M., Parjanen, S., Rantala, T., Salminen, J., Pekkola, S., \& Mäkimattila, M. (2016). Effectiveness of innovation capability development methods. Innovation, 18(4), 513-535.

Wan, X., Cenamor, J., Parker, G., \& Van Alstyne, M. (2017). Unraveling platform strategies: A review from an organizational ambidexterity perspective. Sustainability, 9(5), 734.

Yeşil, S., \& Dereli, S. F. (2013). An Empirical Investigation of the Organisational Justice, Knowledge Sharing and Innovation Capability. Procedia - Social and Behavioral Sciences, 75, 199-208. https://doi.org/https://doi.org/10.1016/j.sbspro.2013.04.023

Zainal, A. Y., Yousuf, H., \& Salloum, S. A. (2020). Dimensions of agility capabilities organizational competitiveness in sustaining. (Ed.),^(Eds.). Joint European-US Workshop on Applications of Invariance in Computer Vision. 